\title{
ROLE OF TRUST IN ADOPTING CONSUMER SOCIAL RESPONSIBLE BEHAVIOUR IN THE CONTEXT OF WATER USE IN DOMESTIC HOUSEHOLDS
}

Cornelis G.W. Caspers

\section{ABSTRACT}

The central theme in this article is Consumer Social Responsibility (CnSR) in the context of sustainable water consumption at home. In this paper, a conceptual SEM model will be tested based on the Theory of Planned Behaviour. This model focuses on the role of trust mediated by CnSR attitude, in influencing water conservation behaviour. Using a sample of 493 respondents, SEM analysis results show that trust in water companies and general trust disposition have significant effect on CnSR attitude. Attitude is approached via environmental, economic and social angle, covering three (triple) mentioned domains of sustainability each with an associated minimum (bottom) required level (line) also known as the Triple Bottom Line (TBL).

Keywords: Sustainability, Triple Bottom Line, CnSR, Water Sector, SEM, Theory of Planned Behaviour, Trust.

JEL Classification: $M 30$

\section{INTRODUCTION}

Discussions in literature related to sustainability were, for a long time, primarily driven by the supply side of the market, wherein corporations were put in the spotlight. In this context Corporate Social Responsibility (CSR) has become a major research field for many scholars (Carroll 1979; Matten, Crane and Chapple 2003). Despite all such attention, it seems a challenge to define CSR unambiguously (van Marrewijk 2003; Waddock 2004). For example, the adjective 'social' very often leads to confusion because it normally covers more than just the social domain. However consensus seems to have been reached about CSR referring to a balancing trade-off between the minimum economic, social and environmental requirements ('Triple Bottom Line') in doing business (Elkington 1997). It can be defined as "a one that proactively offers social benefits or public service and voluntarily minimizes practices that harm society regardless of any legal requirement" (Vitell 2015, p.767).

Apart from the above-mentioned Triple Bottom
Line (TBL) domain scoping, the inclusion of other stakeholders (see the above-mentioned 'society' by Vitell), in addition to corporations, became a point of research interest (Devinney et al. 2006; Caruana and Chatzidakis 2013; Vitell 2015). Attention now became directed to the notion that all market actors in society are accountable 1) to themselves in terms of responsible choices made, and 2) to all other actors in society in terms of non-violating or even serving their primary interests. In this article, the consumer side is an angle

Cornelis G.W. Caspers, MSc

PhD Candidate

School of Economics and Business

University of Sarajevo

E-mail: casperskees@gmail.com

Address: 34, Chavchavadze Avenue

0179 Tbilisi

Georgia 
of interest, and therefore it becomes interesting as to how this target group integrates sustainability into their thinking, decision making and behaviour. From this perspective Devinney et al. (2016) were one of the first who introduced the concept of Consumer Social Responsibility (hereinafter CnSR) or framed as 'the other CSR'. CnSR can be applied to all kinds of services and products, and therefore also to 'water'.

The sustainability literature focused on the water sector predominantly pays attention to water conservation behaviour in situations of envisaged water shortages (Gilg and Barr 2006; Jorgensen, Graymore and O'Toole 2009; Martinez-Espineira, Garcia-Valinas and Nauges, 2014; Willis et al. 2011; Fielding et al. 2012). Our study takes place in an environment in which water is not a particularly scarce resource (the Netherlands). Research aimed at sustainability regularly emphasises environmental attitude/concern as an antecedent of sustainable consumption. The author will further elaborate along this line of thinking, but will also pay attention to the other two 'triple bottom line (TBL)' attitude perspectives; the economic and social ones. After all, water conservation may also be undertaken for economic (money-driven) reasons (Clark and Finley 2007; Lowe, Lynch, and Lowe 2015). Furthermore, social concerns (attitude) may also impact on water conservation behaviour (Syme and Nancarrow 2012). Finally the Theory of Planned Behaviour (TPB) (Ajzen, 1985) will be used as an underpinning theory, linking attitudes with behaviour (sustainable water consumption).

Consumer trust becomes relevant when consumers cannot be sure that their interests are being optimally served. In the case of a regulated market, involving governmental market interference, such concerns may prevail. Interference can impact consumers' trust with ramifications for consumer attitudes (Peters et al. 2007; Grimmelikhuijsen et al. 2013) and ultimately for behaviour. The role of trust in this article used as an antecedent of sustainable water consumption has not been often addressed in the water sector literature. Scholars who did address trust have frequently approached it in a qualitative way (Jorgensen, Graymore and O'Toole 2009; Probert et al. 2014; Jenkins, Pericli, and Palframan 2016). However, rarely is trust approached in a quantitative way (Miller and Buys 2008; Lowe, Lynch, and Lowe 2015). In our study we also research trust in a quantitative way, viewed from three angles; (1) trust in water companies, (2) trust in government and (3) general trust disposition. Our research therefore is quite unique, and expands existing knowledge about how trust behaves in the water sector, and in particular, in an environment with ample water availability.

\section{LITERATURE REVIEW}

The theory of planned behaviour (Ajzen 1985) forms the underlying framework of this study and is considered as "one of the most frequently cited and influential models for the prediction of human social behaviour" (Ajzen 2011, p.1113). Attitudes, social norms (SN), and perceived behavioural control (PBC) influence intentions that consequently affect behaviour. This theory (TPB) is used by scholars in many different ways, ranging from a 'limited version' (wherein only a few of the mentioned variables are used) up to an 'extended version' (wherein many more variables are included). A meta-analysis study undertaken by Armitage and Conner (2001) found that TPB accounted for $27 \%$ (behaviour) and 39\% (intention) of the variance explained. Later Bamberg and Möser (2006) found in their meta-analysis study percentages of $27 \%$ (behaviour) and even 52\% (intention). Steg and Vlek (2009) put forward the view that TPB has been rather successful in explaining various types of environmental behaviour, including water use behaviour.

"Sustainable consumption (SC) often involves a conflict between individual and collective interests" (Steg 2015, p.70) which was already nicely demonstrated by Hardin (1968). In his 'tragedy of the commons' a herdsman wants his cattle to graze the common fields. The more cattle he lets graze, the higher his revenue becomes. Other herdsmen see his success and want to do the same. After a while there comes a point in time when too many cattle are overgrazing the commons, with near future effects on the availability of grass for everyone, with an associated decline in cattle production revenues. This example illustrates that we, all people, are sharing planet earth and often inadequately adjust our behaviour in order to neutralise the downside effects of such behaviour resulting in such features as over-extracting natural resources, global warming, pollution, water shortages, etc. Sustainability has become a mainstream topic in the economic literature (Carrol 1979) within a production entrepreneurial context, often referred to as Corporate Social Responsibility (CSR). Emphasis on sustainability from a consumer behaviour (consumption) perspective is addressed by the concept of Consumer Social Responsibility (CnSR). Note that CnSR narrowly envisaged is dealing with how consumers deliberately 'helped (pushed)', by their consumption choices (based on ethical/moral values) with regard for eco-products/green products (e.g. fair trade), companies in being sustainable. Caruana and Chatzidakis (2013, p.578) stretched this traditional narrow CnSR view, suggesting that "consumers act upon various motives that complement and compete with ethical ones". They present a multiple-level and 
multiple-agent conceptualization of the 'other CSR (CnSR)' concept. In their broader view, they envisage CnSR as 'the application of instrumental, relational and moral logics (motives) by individuals, group, corporate and institutional agents seeking to influence a broad range of consumer-oriented responsibilities'. Levels run from micro (consumers), through meso and macro, to supramacro (inter-governmental organisations, e.g. the UN). Agents can be consumers, families, governments, corporations, NGOs and the motives can be various (not confined to the more classical ethical/moral motives and responsibilities). Anyway, CSR and CnSR are closely related as was also posited by Vitell (2014, p.767), “CSR needs to be accompanied by CnSR" agreeing with Devinney et al. (2006, p.35) who argued for "aligning CSR and CnSR". Traditionally, environmental issues have received the greatest attention in the CSR literature.

The following presented theoretical constructs are all used as variables in our conceptual model. Water conservation attitude TPB studies are regularly approached in a uni-dimensional, or more often in a two-dimensional TBL perspective (Clark and Finley 2006; Willis et al. 2011; Fieldings et al. 2012; Dolnicar, Hurlimann, and Grün 2012; Ho, Lin, and Lai 2016; Kang et al. 2017). Combinations of environmental and economic approaches as well as combinations of social and environmental foci occur most frequently. There is an exception in the case of Lowe, Lynch, and Lowe (2015) who used a construct wherein all three TBL dimensions can implicitly be recognised. We propose to do the same, but now explicitly define these three TBL perspectives as part of our CnSR attitude construct.

A second theoretical construct used in our model, as an antecedent of attitude, is trust. Without precisely defining trust, Thomas (1998) describes how he envisages trust: "the more we calculate the intentions of others, expect something in return, and subsequently monitor their performances, the less we are exhibiting trust. Similarly, the more others take our interest into account, putting their interest aside in the process, the more they are worthy of our trust" (p.169/170). Thomas (1998, p.167) argued that trust can be seen as a multifaceted complex construct with "cognitive, emotional and behavioural components that operate at both the interpersonal and institutional [organisational] levels". It may be safe to conclude, that "the relative importance of trust depends upon the nature and complexity of interaction with other people" (Gefen 2000, p.727). Therefore, in this study, three trust constructs are used: (1) trust in water companies, (2) trust in government and (3) general trust disposition. In the water sector literature, trust (and fairness) is recognised as a variable in explaining water conservation behaviour (Syme, Nancarrow, and McCreddin 1999, 2012; Jorgensen, Graymore, and O'Toole 2009) although not often operationalised. Up to now, trust seems to be more commonly addressed in qualitative research than in quantitative research. Probert et al. $(2014$, p.230) received back from interviewees that "[when] other consumers are doing the same [using water in a cautious way], water saving behaviour is likely to be greater if the consumer trust that the water company is doing all they can to preserve water". This clearly supports the earlier-mentioned observation that CSR and CnSR need to be aligned (Devinney et al. 2006; Vitell 2014). In their qualitative research, Jenkins, Pericli, and Palframan (2016) addressed trust in relation to the perceived fairness of water price/ tariff increases. They advise government and water companies to develop campaigns focusing on building trust between stakeholders. To the author's knowledge, Lowe, Lynch, and Lowe (2015) were one of the very few in addition to Miller and Buys (2008) to empirically use quantitative research to test the relevance of trust in authorities with outcome variable 'water conservation intention and behaviour'. Interpersonal trust and/or the general disposition of trust have not been explicitly encountered in the water sector literature by the author of this article, except for the aforementioned Probert et al. (2014, p.230) reference, wherein "other consumers are doing the same [water conservation]", suggesting the same kind of behaviour, when there is mutual trust in the water company. Another possible link to interpersonal (dis)trust may be found in research conducted by Corral-Verdugo, Frias-Amenta, and Gonzales-Lomeli (2003) who investigated the role of anti-social behaviour in relation to water conservation.

The third variable in our conceptual model is the TPB outcome variable: CnSR behaviour (water consumption). A number of scholars (Lam 1999, 2006; Trumbo and O'Keefe 2005; Clark and Finley 2006) have confined themselves to sustainable water use intentions and do not include the ultimate sustainable water use (behaviour) construct in their models as an outcome variable. Others (Fielding et al. 2012; Lowe, Lynch and Lowe 2015; Ho, Lin, and Lai 2016; Kang et al. 2017) use a combination of such intention and behaviour while still others use only behaviour (MartinezEspineira, Garcia-Valinas, and Nauges 2014; Bronfman et al. 2015; Wells et al. 2016). Nonetheless, both CnSR water consumption intentions and behaviour address issues such as showering for shorter periods, repairing leaking taps, using dual toilet flushers, full loading of washing machines and dishwashers, etc. 


\section{RESEARCH MODEL AND HYPOTHESES}

This article addresses the effect of trust in driving Consumer Social Responsible behaviour being mediated by CnSR-related attitudes. Noblet and Teisl (2015) stress the importance of trust in certifying agencies in relation to consumer willingness to pay more for eco-labelled products. Furthermore, Caruana and Chatzidakis (2013, p.577) also underline the importance of trust in a sustainability context, "that encapsulate consumer's faith that corporations have not exploited humans, animals, or ecosystems, broken laws, or violated codes of conduct in the product's production".

Trust in our model is composed of: (1) trust in water companies, (2) trust in government and (3) general trust disposition. The idea behind such a choice is that directly or indirectly they jointly cover all the most important actors in the water sector. The proposed research model is shown in Figure 1.

The extent literature shows that trust in a company influences the purchasing intention and/or the behaviour of customers (Kang and Hustvedt 2013; Gefen and Straub 2004) while some other scholars (Pivato, Misani, and Tencati 2008) addressed the role of trust as mediator in companies engaged in Corporate Social Responsibility (CSR) behaviour leading to certain consumer behaviour (loyalty), that can be assumed will potentially provoke rehearsal purchases. Furthermore, Gefen and Straub (2004) summarize the variety of trust dimensions in a number of conducted researches, ranging from integrity, benevolence, ability, openness, reliability, predictability, competence/ability, honesty, to fairness. These classifications clearly fully underline the earlier observation made by Thomas, that trust can be seen as a multifaceted complex construct. Without any reservation, water companies do play an important role in the water sector. Their main task is to provide potable water on a $24 / 7$ basis at a reasonable price to their customers. Furthermore, they communicate with their clients (consumers) about various subjects (tariff changes, water quality, potential disruptions of supply, complaints, etc.). Experiences regarding this performance/behaviour and correct communication in relation to the fact as to whether or not the company has kept up to its made promises creates a certain trust that people have in the water company. Continuing further with trust in government, Peters et al. (2007, p.192) demonstrate that "institutional trust is a moderate predictor of attitudes towards food biotechnology in the USA but not in Germany", showing the situational condition of the trust-attitude relationship. Trust is here seen as a mechanism for uncertainty reduction. Furthermore, Grimmelikhuijsen et al. (2013) investigated the role of trust in government in a two country context (the Netherlands and South Korea) also showing different outcomes. Government involvement in the NL water sector is determined in legislation ('drinking water act'). The government approves tariffs, sets safety and quality standards of distributed water, limits the return on capital of water companies, orders regular benchmarks in the sector, supports a sustainable corporate policy, and is a shareholder in the water companies (plc). Whether the general public (consumers)

Figure 1. Conceptual Model

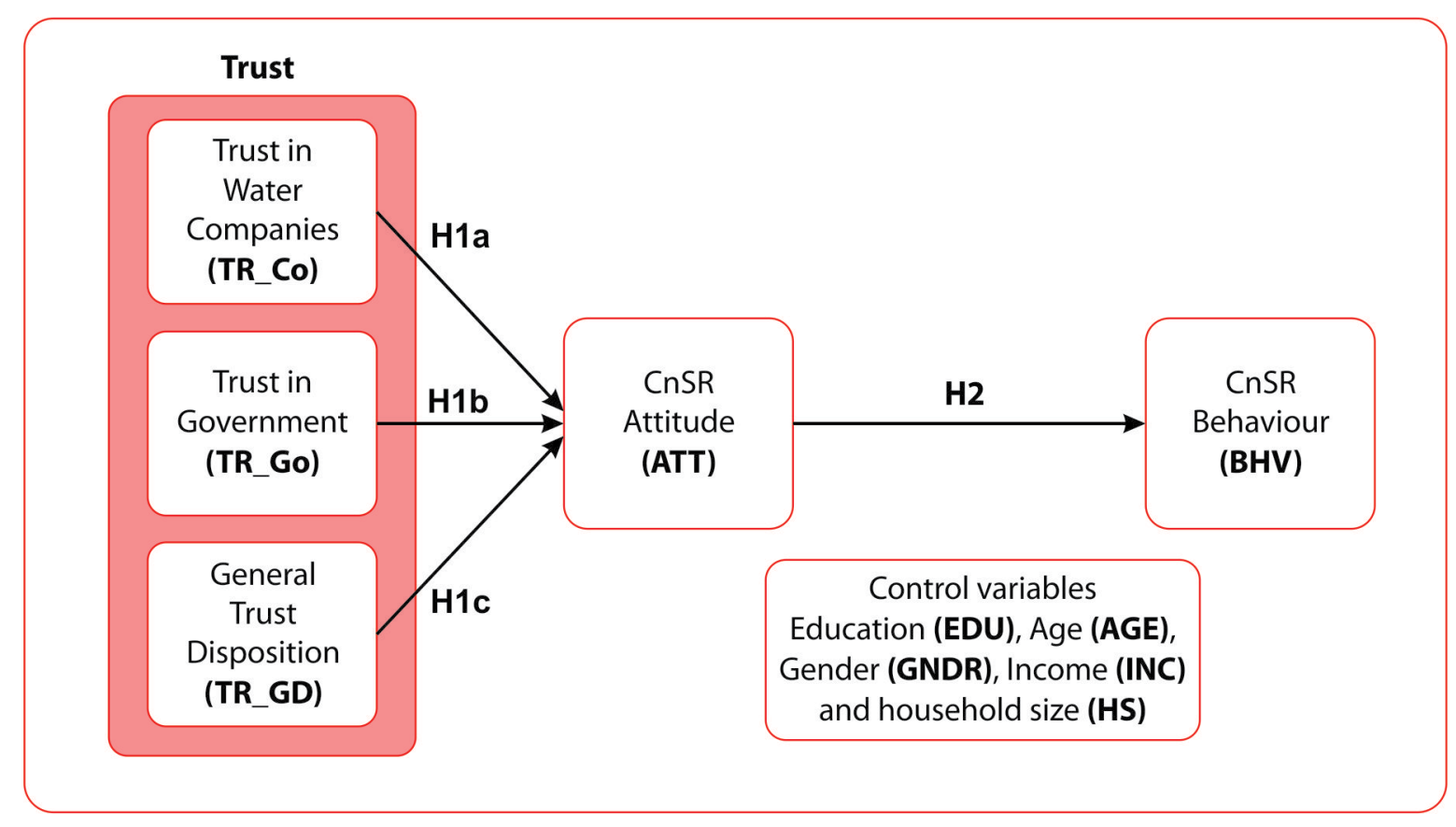


are aware of such a broad governmental role wherein the interests of consumers are well served can be questioned. The third and final trust perspective in our research is general trust disposition. Gefen (2000) and Gefen and Straub (2004) describe how general trust (in people and society) impacts consumer (purchase) behaviour in a positive way. The idea is that in society, initial trust disposition depends on many factors such as (past) general experiences, exposure to information/communication, stories of family and friends, assessment of the good/bad behaviour of other societal actors, etc. etc. So we postulate the following three hypotheses ( $\mathrm{H} 1 \mathrm{a}, \mathrm{H} 1 \mathrm{~b}$ and $\mathrm{H} 1 \mathrm{c})$.

$\mathrm{H} 1$ : Trust has a positive effect on CnSR Attitudes towards Water Conservation.

- H1a: Trust in water companies has a positive effect on CnSR Attitudes towards Water Conservation

- H1b: Trust in government has a positive effect on CnSR Attitudes towards Water Conservation

- H1c: General Trust Disposition has a positive effect on CnSR Attitudes towards Water Conservation

Various researchers have demonstrated that attitude can be considered as a key variable in the Theory of Planned Behaviour (Shaw, Shiu, and Clarke 2000; Clark and Finley 2007; Wells et al. 2016) in relation to the final outcome variable (in our case behaviour). Following this theory, it is assumed that attitude (indirectly) influences behaviour. Wells et al. $(2016$, p.66) hypothesized that "attitudes towards water [and energy] saving positively affect water [and energy] saving behaviour". Also Kang et al. (2017) investigated whether or not sustainable water consumption attitude had a direct relationship with sustainable water consumption behaviour. In line with these above-mentioned studies we hypothesize:

H2: CnSR Attitude towards Water Consumption has a positive impact on CnSR Behaviour towards Water Consumption.

The chosen 5 control variables are a selection of control variables often used in the water consumption context (education, age, gender, income and household size).

\section{SAMPLING AND RESEARCH METHOD}

\subsection{Sampling}

Correct sampling is dependent upon many things such as compliance with normality assumptions, research methods used, etc. Hair et al. (2010) suggest, as a rule of thumb, to strive for a desired number of 5 cases per observed variable. As our model involves 23 observed variables including control variables (see section 4.3: measurement model and analysis), the rule of thumb calculation will lead us to a sample size of 115 . We continued to analyse compliance of data with normal distribution assumptions. It turned out that our observed variables were not normally distributed. The good news is "for sample sizes of 200 or more these effects [non-normality] may be negligible" (Hair et al. 2010, p.72). One can also look at the sample size from the concept of power assessment of a model. Note that the author chose structural equation modelling (SEM) as the research technique used. The power of a test is defined as the probability that an incorrect model will be rejected, and focuses on type Il errors, to be expressed in rate 1- $\beta$ (Diamantopoulos and Siguaw 2009). MacCallum, Browne and Sugawara (1996) have worked out tables wherein the power of a test is a function of the degrees of freedom (df) in the model, given a certain significance level a (quite often 0.05 ) and sample size N. It turns out to be, for sample sizes of 400-500 cases with more than 30 degrees of freedom, the power becomes more than 0.8 which is considered sufficient for practical purposes (Diamantopoulos and Siguaw 2009).

Over the summer 2018, data were collected based on self-reporting by respondents making use of a marketing research bureau (Panelclix). Panel members signed up with Panelclix through various sources, and were selectively targeted (in representative and/ or stratified surveys). This was done in such a way that the sample safeguarded representativeness by matching in an acceptable way the characteristics of the Dutch population. The panel participants received a small financial reward to complete the survey. The online web survey was developed by the author in conformity with Dillman, Smyth and Christian (2009) guidelines, and incorporating mandatory question responses plus providing completion time per question and per survey. In total, Panelclix provided 665 (partly) filled out questionnaires. After quality assessment, 493 cases remained. As was just previously noted, such a sample size should be sufficient for our research even in the case of non-normally distributed data.

\subsection{Measures}

The by Kang and Hustvedt (2013) used trust scale, based on the scale developed by Erdem and Swait $(1998,2004)$, was adapted to measure trust in a water company and in government. This scale consists out of 5 items (using a Likert 9-point scale). General trust 
is measured using a 4-item scale developed by Gefen (2000, 2004). For measuring attitude, a scale presented in one of the marketing scales handbooks (Bruner II 2009; Bearden et al. 2011) became the starting point. This scale 'Attitude towards the product/brand' bipolar scale (\#108 from Bruner II Marketing Scales Handbook) was adapted to a water and TBL context. For the behaviour scale, the author adapted the scale used by Bronfman et al. (2015) now with focus on the efficient use of electric appliances in the household (washing machine and dishwasher). All the scales in previous research show acceptable validity and reliability scores.

\subsection{Measurement Model Analysis}

The two-step approach suggested by Anderson and Gerbing (1988) was taken as starting point for confirmative factor analysis (CFA) in Lisrel (version 8.71) using covariance matrix as input. This approach distinguishes between first assessing the so called 'measurement model' and then proceed with evaluating the 'structural model'. Table 1 shows the properties (construct items, factor loadings, Average Variance Extracted (AVE), Composite Reliability (CR), and associated fit indices) of the scales we used.

Table 1. Scales Properties and Items

Loadings

Trust in Water Company (Kang and Hustvedt 2013)

9-point Likers scale ( $1=$ disagree, ... 5=neither agree or disagree, ... 9= agree), AVE=0.797 and CR=0.951

* The water company in my community does not pretend to be something it is not.

* The water company in my community product/services' claims are believable.

* Over time, my experiences with the water company in my community have led me to expect it to keep its promises no more and no less.

* The water company in my community has a reputation you can trust.

* The water company in my community delivers what it promises.

Trust in Government (Kang and Hustvedt 2013)

9-point Likers scale ( $1=$ disagree, ... 5=neither agree or disagree, ... 9= agree), AVE=0.787 and CR=0.936

* The government in my community product/services' claims are believable.

* Over time, my experiences with the government in my community have led me to expect it to keep its promises no more and no less.

* The government in my community has a reputation you can trust.

* The government in my community delivers what it promises.

General Trust Disposition (Gefen and Straub 2004)

7-point Likers scale ( $1=$ disagree, ... 4=neither agree or agree, ... 7= agree), AVE=0.805 and CR=0.943

* I generally trust other people.

* I tend to count upon other people.

* I feel that people are generally well meaning.

* I feel that people are generally reliable.

CnSR Attitude towards water consumption (\#108 from Bruner II Marketing Scales Handbook)

7-point Likers scale, $A V E=0.632$ and $C R=0.837$

Indicate whether sustainable water use at home is <see statements below $>$ for you?

* environmentally non effective $<1, . .4 . . ., 7>$ environmentally effective

* economically no value for money $<1, \ldots .4 \ldots, 7>$ economically value for money

* socially inappropriate $<1, \ldots .4$.. .,7> socially appropriate

CnSR Behaviour towards water consumption (adapted from Bronfman et al 2015)

5-point Likers scale ( 1 =never, .... , 5=always), AVE=0.469 and CR=0.638

What is your actual behaviour in relation to: <see statements below $>$ ?

* At home, I have a full load of laundry before putting it in the washing machine.

* At home, I use the dish washer only when it is fully loaded. 
Table 2. Correlation Matrix (Model Constructs)

\begin{tabular}{|l|cccc|}
\hline & 1 & 2 & 3 & 4 \\
\hline Trust in Water Companies (1) & 1.000 & & & \\
Trust in Government (2) & 0.042 & 1.000 & & \\
General Trust Disposition (3) & 0.117 & 0.214 & 1.000 & 1.000 \\
CnSR Attitude (4) & 0.375 & 0.142 & 0.218 & 0.269 \\
CnSR Behaviour (5) & 0.131 & -0.076 & 0.031 & 1.000 \\
\hline
\end{tabular}

The overall results of the measurement model are acceptable. Convergent validity examines the following; "items that are indicators of a specific construct should converge or share a high proportion of variance in common" (Hair et al. 2010, p.709). Indicators such as Cronbach alpha, Average Variance Extracted (AVE) and Composite Reliability (CR) provide information as to whether convergent validity is imminent. AVE presents "the amount of variance that is captured by the construct in relation to the amount of variance due to measurement error" (Fornell and Larcker 1981, p.45). AVE with a value more than 0.5 indicates extracted variance of indicators is greater than the error variance and suggests adequate convergence. Almost all our constructs comply with the 0.5 threshold, with the exception of the CnSR behaviour construct ( $A V E=0.469$ ) approaching this level. Hair et al. (2010, p.710) state, "high construct reliability $[C R]$ indicates that internal consistency exists, meaning that the measures all consistently represent the same latent construct". As a rule of thumb, $C R$ values of 0.6 and greater are seen as minimum (Bagozzi and Yi 1988), provided that the CRs of other model's constructs are higher than 0.7. Our model complies with this rule of thumb, in that CnSR behaviour is the only construct showing a CR level of less than 0.7 (with 0.638 still above the 0.6 level). Another validity concept, discriminant validity, is also investigated. Ping jr (2004, p.131) states, "correlations with other measures below $|0.7|$ were usually accepted as evidence of measure distinctness and thus discriminant validity". Looking at the presented correlation matrix (Table 2) we can conclude that discriminant validity is assured. The highest correlation $(0.375)$ is between trust in a water company and CnSR attitude, and is well below the 0.7 level.

As we used an adapted attitude scale covering our 3 TBL perspectives it can be interesting to analyse whether Dutch consumers show preference for one of these perspectives in addressing their CnSR attitude. Mean scores of 5.3 (environmental), 5.2 (economic) and 5.3 (social) really did not differentiate, indicating that Dutch consumers valued all three aspects more or less equally. Last but not least, our measurement model's goodness-of-fit indices all scored well above acceptable levels, suggesting good model fit.

\subsection{Structural Model Analysis}

The next step, taken in accordance with Anderson and Gerbing (1988) is assessing the structural model (Table 3). We encountered acceptance of all our hypotheses except for $\mathrm{H} 1 \mathrm{~b}$ (trust in government has a positive effect on CnSR attitudes towards water conservation). Note that the p-levels of the confirmed structural relationships are good (0.01 and 0.001). First we looked at model-1a that confined itself to just structural relationships. The variance explained (behaviour) is $7.3 \%$. We continued with model-1b where we also take the effect of control variables into account. This model explains a variance of $12.9 \%$. In the next paragraph (5), we will discuss whether these results are in line with the results obtained by other scholars. The goodnessof-fit indices of the structural model all comply well with standards.

In order to address the potential shortcomings of our model, we conducted additional analyses. Firstly, we did the same analysis again, but with log-transformed data (to neutralize the skewness of our dataset). All results in terms of the acceptance/rejection of the above-mentioned hypotheses remained the same. Secondly, we recognised the potential common method variance/bias risk (Podsakoff et al. 2003), associated with the chosen data collection method (selfreporting). Both Harman's single factor test and the 'marker variable' approach provided no evidence for a common method variance presence. 
Table 3. Structural Model

\begin{tabular}{lll|}
\hline & Model-la & Model-1b \\
Relationships & & \\
TR_Co --> ATT & $0.26\left(7.03^{* * *}\right)$ & $0.26\left(7.03^{* * *}\right)$ \\
TR_Go --> ATT & $0.06(1.89 \mathrm{~ns})$ & $0.06(1.91 \mathrm{~ns})$ \\
TR_GD --> ATT & $0.14\left(3.30^{* *}\right)$ & $0.14(3.29 * *)$ \\
ATT --> BHV & $0.15\left(3.66^{* *}\right)$ & $0.14\left(3.82^{* *}\right)$ \\
Control variables & & \\
Education (EDU--> BHV) & & $-0.04(-01.20 \mathrm{~ns})$ \\
Age (AGE-->BHV) & & $0.04(2.04 *)$ \\
Gender (GNDR-->BHV) & & $-0.19\left(-3.05^{* *}\right)$ \\
Income (INC-->BHV) & & $0.05(1.71 \mathrm{~ns})$ \\
Household size (HS-->BHV) & & $0.03(1.42 \mathrm{~ns})$ \\
Fit indices & & \\
df & & 198 \\
X2/df & 203 & 1.152 \\
RMSEA & 1.232 & 0.018 \\
SRMR & 0.022 & 0.028 \\
GFI & 0.032 & 0.961 \\
CFI & 0.958 & 0.996 \\
NNFI & 0.994 & 0.995 \\
AGFI & 0.993 & 0.946 \\
R2 & 0.942 & $12.9 \%$ \\
\hline
\end{tabular}

t-value estimate: $* * * * * *$

for our sample size (493), ${ }^{*} \mathrm{p}<0.05^{* *} \mathrm{p}<0.01{ }^{* * *} \mathrm{p}<0.001$ associated critical t-values are: 1.960, 2.576 and 3.292 for $a=0.05, a=0.01$ and $a=0.001$ (all two-tailed)

\section{DISCUSSION}

"[Although] trust has been identified in the water sector and natural resources literature as a key institutional issue" (Jorgensen, Graymore, and O'Toole 2009, p.233), it has not been widely investigated in the environmental psychology literature. Jorgensen, Graymore, and O'Toole (2009) proposed an integrated conceptual model including trust, although not statistically tested, dealing with household water use behaviour. Other scholars in qualitative research also mention the relevance of institutional trust in relation to water use and conservation (Jenkins, Pericli, and Palframan 2016; Probert et al. 2014). To the best of our knowledge, Lowe, Lynch and Lowe (2015) were one of the first to conduct an empirical quantitative study in a drought-affected region of Australia wherein institutional sentiment towards the water authority's management of water was included as a construct. They hypothesized that "more positive institutional sentiment towards the water authority's management of water situation, the stronger the intention to conserve water in future" (Lowe, Lynch, and Lowe 2015, p.14). Water 'authority' was not explicitly further defined, but it doubtlessly covers the water supplier (the company) and probably government as well. This hypothesis was confirmed $(p=0.027)$ and showed a regression coefficient of 0.082. A second quantitative study (Miller and Buys 2008) included trust (and safety) as one of the dimensions of a broader social capital construct, being a predictor of water conservation behaviour (in the case of car washing and gardening). It did not turn out to be significant in their logistic regression model. As already indicated, interest in academia had already occurred with regard to the trust concept that goes further than just institutional trust (water company and government). Positive expectations with regard to conduct of others/neighbours/the community in terms of saving water (inter-personal trust) also became relevant. "When people do not trust others to save water they felt no obligation to save water themselves" (Jorgensen, Graymore, and O'Toole 2009, p.229). Why should you restrain yourself by not 
watering your roses in the garden when your neighbour is extensively irrigating his large garden every day? Also, in their study, Dolnicar, Hurlimann, and Grün (2012) mention 'people who influence' although they did not address this any further in their discussion of the results. In our model, two trust hypotheses in relation to CnSR attitude (water use) were supported (general trust disposition at the $p<0.01$ level and trust in water companies at the $p<0.001$ level). Only the relationship between trust in government and CnSR attitude (water use) was rejected. This speculatively may be explained by the notion that people are probably not fully aware of the role the NL government plays in the water sector (tariff approval, setting quality standards, etc.). Consequently more research would be useful. In terms of the strength of the confirmed two relationships, the relevant path coefficients were 0.26 (for trust in water companies) and 0.14 (for general trust disposition) in relation to CnSR attitude, making trust in water companies the stronger predictor of CnSR attitude (water consumption). The high trust of consumers in NL water companies was also referred to by Hegger et al. (2011). Note that these path coefficients are higher than the regression coefficient obtained (0.082) in the Lowe, Lynch, and Lowe (2015) study. So we are now part of the few pioneers (Miller and Buys 2008; Lowe, Lynch, and Lowe 2015) that operationalized trust in the water sector in a quantitative model as was suggested by Jorgensen, Graymore, and O'Toole (2009). We definitely also belong to the first to distinguish in a quantitative model between the roles of water companies, government and general initial trust played in creating CnSR attitude towards water conservation.

Some scholars, in considering the water sector, confined themselves to a limited TPB model by merely including either intention or behaviour in addition to attitude. The reason for such a choice is mostly not addressed, but probably has to do with the potentially high correlation between the two constructs as also was encountered in our research. The Pearson correlation coefficient between intention and behaviour turned out to be 0.717 just above the threshold (|0.7|) for discriminant validity as mentioned by Ping jr (2004). Syme et al. (2004) conducted SEM analysis wherein home water garden use (behaviour) was an outcome variable. Their extended TPB model showed that attitude played a relatively small role in terms of the strength of the path coefficient. Kang et al. (2017) used both sustainable water intention and behaviour in their model but did not hypothesize a relationship between the two. They found a highly significant correlation between sustainable water conservation attitude and sustainable water behaviour (0.68 at the $\mathrm{p}<0.01$ level). Furthermore, next to attitude, their model included also subjective norms and perceived behavioural controls, and it turned out that the correlation between attitude and sustainable water behaviour was the highest, indicating its relative importance. Ho, Lin and Lai (2016) did run an SEM analysis including both water saving intentions and behaviour. The two constructs had a correlation of 0.672 . Although still below the by Ping jr (2004) mentioned discriminant validity threshold some caution here with regard to such a high correlation seems appropriate. Wells et al. (2016) conducted SEM analysis and hypothesized a relationship (at home) between water and energy saving attitudes and water and energy saving behaviour. Their hypothesis was confirmed with a high path coefficient of 0.637 (at the $p<0.001$ level). Lowe, Lynch and Lowe (2015) confirmed a relationship (using ordinary least squares regression) between the attitude towards water conservation and the intention to conserve water. The associated regression coefficient showed a value of 0.265 at the $p<0.001$ level including socio/economic/demographic control variables in the model. Our results using SEM including control variables demonstrate a path coefficient of 0.14 at the $p<0.001$ level. Regarding the variance explained in our model (ranging between $7.3 \%$ and $12.9 \%$ ) this result does not seem to be exceptional taking into account the fact that attitude defined in TBL terms, not often encountered in similar studies, is the only antecedent of behaviour in our model. Clark and Finley (2014) came up with more or less the same percentages, although in their model water conservation intentions were used instead of behaviour. Furthermore, next to attitude, their model included the TPB variables SN and PBC. On the other hand, Fielding et al. (2012) reached a variance explained of $33 \%$ by using only socio/economic/demographic variables. The addition of TPB variables (ATT, SN, PBC) improved this percentage by a mere $2 \%$. So mixed results have been encountered in various pieces of research using different variables. We may conclude that the model results we obtained do not seem completely out of line.

Let us continue with how scholars in the field under investigation (water conservation) look at the possible influence of an array of more socio/economic/ demographic aspects that impact the water consumption of household consumers (or their intention to save water). In the relevant literature, a wide variety of socio/economic/demographic variables can be encountered (Gilg and Barr 2006; Corral-Verdugo, Fraijo-Sing, and Pinheiro 2006; Lam 2006; Clark and Finley 2007; Fielding et al. 2012; Martinez-Espineira, Garcia-Valinas, and Nauges 2014; Lowe, Lynch, and Lowe 2015; Shan et al. 2015). We chose to focus on the 
following frequently mentioned variables describing the following consumer characteristics: (1) education level, (2) age, (3) gender, (4) income and (5) household size. Unfortunately, not all the above-mentioned conducted studies reached the same conclusions. To start with gender, Corral-Verdugo et al. (2006) found that women and adults are more engaged in water conservation. Our results support this conclusion. In contrast, Shan et al. (2015) came to the conclusion that women take longer showers than men, and therefore consume more water at home. Lam (2006) found that gender and age were relatively unimportant variables. Gilg and Barr (2006) showed that age plays a role (older people are more likely to be environmentally engaged than younger people). In our model, age is envisaged as a significant variable, although with a very small path coefficient (0.04). Fielding et al. (2012) and Clark and Finley (2007) found that income is related to water use while others did not find such a significant relationship (Lowe, Lynch, and Lowe 2015). Our results matched the conclusions that Lowe, Lynch and Lowe (2015) reached. Fielding et al. (2012) demonstrated that education has no significant relationship with water conservation, while Clark and Finley (2007) found the opposite conclusion. Our conclusion here aligns with those of Fielding et al. (2012). Regarding household size, Clark and Finley (2007) did not find a significant relationship with water conservation intentions. In contrast, Fielding et al. (2012) and MartinezEspineira, Garcia-Valinas, and Nauges (2014) found the opposite. In our model, household size did not play a significant role. Our block of socio/economic/demographic control variables explained $5.6 \%$ of the variance explained, not far out of line with the $5.1 \%$ found by Clark and Finley (2007). Lam (2006) found that educational training and living in an apartment with more than 5 stories compared with a detached house accounted for $4.2 \%$ of the variance explained. Fielding et al. (2012) demonstrated that their block of control variables showed a variance explained of $33 \%$, which can be considered as exceptionally high. It should be mentioned that none of the above-mentioned scholars used the same block of control variables. Therefore the above made comparisons should be interpreted with caution.

\section{CONTRIBUTIONS TO RESEARCH AND LIMITATIONS \\ 6.1 Contributions to research and future research suggestions}

Our study is one of the few studies in the water sector aimed at a country/region where water is amply available. Most research focuses at countries/regions where water is a scarce resource. Therefore it provides additional insight into how TPB relationships in such a context matches with the same kind of relationships in other water availability settings. Secondly, our research approached CnSR attitudes (water consumption) by the all-inclusive TBL concept (environmental, economic and social) while most other scholars confine themselves to a combination of only two TBL perspectives. However, it should be noted that Dutch consumers did not show a clear preference for one of the perspectives over the others. It would be interesting to see whether or not this statement also holds in other countries and/or markets. Thirdly, we were able to quantify in a water context setting the trust relationships with attitude. So far only a few other scholars (Miller and Buys 2008; Lowe, Lynch, and Lowe 2015) have included trust in their quantitative models. We would appreciate more research wherein trust in relation to water consumption attitude/behaviour is conducted, and would be curious to find out whether the role of trust in government would differ in countries and/or markets where government plays a more visible role (compared with the $\mathrm{NL}$ ), or is associated in a very negative way concerning water regulation/ management in society.

Regarding the practical implications, our research clearly demonstrated the role water companies have in terms of trust towards CnSR attitudes. Therefore the trustworthy water company seems the right organisation to influence consumers' attitudes (e.g. via all kinds of communication) regarding sustainable water use. In doing so there is no preferred TBL perspective (environment, economic, social) to emphasize. Influencing consumers via the general disposition of trust, also an option, seems to be less preferable in terms of its impact on CnSR attitude (the associated path coefficient of 0.14 is much lower than the 0.26 showed by trust in a water company).

\subsection{Limitations}

All research faces limitations, and our survey is no exception. Starting with our data, they did not comply with normality assumptions. We log-transformed the data and the results in terms of confirming/rejecting our hypotheses did not change. The model turned out to be robust, fully in line with the notion that SEM analysis conducted with the maximum likelihood extraction method produces robust models (Diamantopoulos and Siguaw 2009; Vieira 2011). A relatively large sample size (493) also contributed in mitigating the possible negative effects of non-normality compliance. 
Another limitation is the confined scope of the TPB model we used in terms of the used variables. On the other hand, by doing so, we were able to fully concentrate on the effects that trust has on CnSR attitude. Another restriction already briefly referred to can be found in the geographical focus of the sample to the Netherlands only.

Although construct (convergent) validity was in general good, our TPB outcome variable CnSR behaviour showed an AVE of 0.469 almost approaching the threshold target of 0.5 .

Finally, our research is based on self-reporting. As was already discussed, such a research approach could be liable to distortion. Nevertheless, the additional analysis undertaken, with a marker variable and Harman's single factor test, showed no evidence of such distortion.

\section{REFERENCES}

Ajzen, I. 1985. From intentions to actions: A theory of planned behaviour. Action-control: From cognition to behaviour, edited by J. Kuhl \& J. Beckman, 11-39. Heidelberg: Springer

Ajzen, I. 2011. The Theory of Planned Behaviour: Reactions and reflections. Psychology and Health, 29 (9): 1113-1127

Anderson, J. C. and Gerbing, D.W. 1988. Structural Equation Modeling in Practice: A Review and Recommended TwoStep Approach. Psychological Bulletin, 103 (3): 411-423

Ansoff, H.I. 1970. Corporate Strategy: An Analytic Approach to Business Policy For Growth And Expansion. Great Britain: Penguin

Armitage, C. and Connor, M. 2001. Efficacy of the theory of planned behaviour: A meta-analytic review. British Journal of Social Psychology, 40: 471-499

Bagozzi, R.P. and Yi, Y. 1988. On the Evaluation of Structural Equation Models. Journal of the Academy of Marketing Sciences, 16 (1): 74-94

Bamberg, S. and Möser, G. 2006. Twenty years after Hines, Hungerford, and Tomera: A meta-analysis of psychosocial determinants of pro-environmental behaviour. Journal of Environmental Psychology, 27: 14-25

Bearden, W.O., Netemeyer, R.G. and Haws, K.L. 2011. Handbook of Marketing Scales. Multi-item Measures for Marketing and Consumer Behavior Research. (3th edition). California India UK Singapore: Sage Publications Inc.

Bronfman, N.C., Cisternas, P.C., Lopez-Vazquez, E., de la Maza, C. and Oyanendel, J.C. 2015. Understanding Attitudes and Pro-Environmental Behaviours in a Chilean Community. Sustainability, 7: 14133-14152

Bruner II, G.C. 2009. Marketing scales handbook, a Compilation of Multi-ltem Measures for Consumer Behaviour \& Advertising Research, Volume 5, Carbondale/llinois/USA: GCBII Productions
Carroll, A.B. 1979. A Three-Dimensional Conceptual Model of Corporate Social Performance. Academy of Management Review, 4 (4): 497-505.

Caruana, R. and Chatzidakis, A. 2014. Consumer Social Responsibility (CnSR): Toward a Multi-Level, Multi-Agent Conceptualization of the 'Other CSR'. Journal of Business Ethics, 121 (4): 577-592

Clark, W.A. and Finley, J.C. 2007. Determinants of Water Conservation Intention in Blagoevgrad, Bulgaria. Society and Natural Resources, 20: 613-627

Corral-Verdugo, V., Frias-Armenta, M., Perez-Urias, F., OrdunaCabrera, V. and Espinoza-Gallego, N. 2002. Residential Water Consumption, Motivation for Conserving Water and the Continuing Tragedy of the Commons. Environmental Management, 30 (4): 527-535

Corral-Verdugo, V., Frias-Amenta, M. and Gonzales-Lomeli, D. 2003. On the Relationship Between Antisocial and AntiEnvironmental Behaviors: An Empirical Study. Population and Environment, 24 (3): 273-286

Corral-Verdugo, V., Fraijo-Sing, B. and Pinheiro, J.Q. 2006. Sustainable Behavior and Time Perspective: Present, Past and Future Orientations and Their Relationship with Water Conservation Behavior. Interamerican Journal of Psychology, 40 (2): 139-147

Devinney, T.M., Auger, P., Eckhardt, G. and Birtchnell, T. 2006. The other CSR: Consumer Social Responsibility. Stanford Soc. Innovation Rev., 4 (3): 30-37

Diamantopoulos, A. and Siguaw, J.A. 2009. Introducing Lisrel. London: Sage Publications Ltd

Dillman, D.A., Smyth, J.D. and Christian, L.M. 2009. Internet, Mail and Mixed-mode SURVEYS the Tailored Design Method. Third Edition. New Jersey: John Wiley \& Sons, Inc.

Dolnicar, S., Hurlimann, A. and Grün, B 2012. Water conservation behaviour in Australia. Journal of Environmental Management, 105: 44-52

Elkington, J. 1997. Cannibals with Forks: The Triple Bottom Line of 21th Century Business. Oxford, UK: Capstone Publishing Ltd.

Erdem, T. and Swait, J. 1998. Brand Equity as a Signaling Phenomenon. Journal of Consumer Psychology, 7 (2): 131-157

Erdem, T. and Swait, J. 2004. Brand Credibility, Brand Consideration, and Choice. Journal of Consumer Research, 31 (1): 191-198

Fielding, K.S., Russell, S., Spinks, A. and Mankad, A. 2012. Determinants of household water conservation: The role of demographic, infrastructure, behavior, and psychosocial variables. Water Resources Research, 48, W10510, doi: 10.1029/2012WR012398

Fornell, C. and Larcker, D.F. 1981. Evaluating Structural Equations Models with Unobservable Variables and Measurement Error. Journal of Marketing Research, 18: 39-50 
Freeman, R.E. 1984. Strategic Management. A Stakeholder Approach. Boston: Pitman

Gefen, D. 2000. E-commerce, the Role of Familiarity and Trust. Omega , - the International Journal of Management Science 28:725-737

Gefen, D. and Straub, D.W. 2004. Consumer trust in B2C eCommerce and the importance of social presence: experiments in e-Products and e-Services. Omega - the International Journal of Management Science, 32: 407-424

Gilg, A. and Barr, S. 2006. Behavioural attitudes towards water saving? Evidence from a study of environmental actions. Ecological Economics, 57: 400-414

Grimmelikhuijsen, S., Porumbescu, G., Hong, B. and Im, T. 2013. The Effect of Transparency on Trust in Government: A Cross-National Comparative Experiment. Public Administration Review, 73 (4), 575-586.

Hair, J.F., Black, W.C., Babin, B.J. and Anderson, R.E. 2010. Multivariate Data Analysis. A Global Perspective, $7^{\text {th }}$ ed. New Jersey: Pearson Prentice Hall

Hardin, G. 1968. The Tragedy of the Commons. Science, 162: 1243-1248

Hegger, D.L.T., Spaargaren, G., van Vliet, B.J.M. and Frijns, J. (2011). Consumer-inclusive innovation strategies for the Dutch water supply sector: Opportunities for more sustainable products and services. NJAS-Wageningen Journal of Life Sciences, 58: 49-56

Ho, F.J., Lin, Y.J. and Lai, W.L. 2016. Exploration of Human Behavior of Water-Saving under Climate Change using Expanded Theory of Planned Behavior Model. International Journal of Science and Technology, 2 (3): 22-39

Jenkins, J.O., Pericli, A. and Palframan, L. 2016. Customer Attitudes to Water Use and its Conservation. British Journal of Environment \& Climate, 6 (3): 170-178

Jorgensen, B., Graymore, M. and O'Toole, K. 2009. Household water use behaviour: An integrated model. Journal of Environmental Management, 91: 227-236

Kang, J. and Hustvedt, G. 2013. Building Trust Between Consumers and Corporations: The Role of Consumer Perceptions of Transparency and Social Responsibility. Journal of Business Ethics, 125 (2): 253-265

Kang, J., Grable, K., Hustvedt, G. and Ahn, M. 2017. Sustainable water consumption: The perspective of Hispanic consumers. Journal of Environmental Psychology, 50: 94-103

Lam, S.P. 1999. Predicting Intentions to Conserve Water from the Theory of Planned Behavior, Perceived Moral Obligation, and Perceived Water Rights. Journal of Applied Social Psychology, 29: 1058-1071

Lam, S.P. 2006. Predicting Intention to Save Water: Theory of Planned Behavior, Response Efficacy, Vulnerability, and Perceived Efficiency of Alternative Solutions. Journal of Applied Social Psychology, 36: 2803-2824
Lowe, B., Lynch, D. and Lowe, J. 2015. Reducing Household Water Consumption: A Social Marketing Approach. Journal of Marketing Management, 31 (3-4): 378-408

MacCallum, M.C., Browne, M.W. and Sugawara, H.M. 1996. Power Analysis and Determination of Sample Size for Covariance Structure Modeling. Psychological Methods, I (2): 130-149

Martinez-Espineira, R., Garcia-Valinas, M.A. and Nauges, C. 2014. Households' pro-environmental habits and investments in water and energy consumption: Determinants and relationships. Journal of Environmental Management, 133: 174-183.

Matten, D., Crane, A. and Chapple, W. 2003. Behind the Mask: Revealing the True Face of Corporate Citizenship. Journal of Business Ethics, 45: 109-120

Miller, E. and Buys, L. 2008. The impact of social capital on residential-affecting behaviours in a drought-prone Australian community. Society and Natural Resources, 21: 244-257

Nancarrow, B.E., Smith, L.M. and Syme, G.J. 1996/7. The ways people think about water. Journal Environmental Systems, 25 (1): 15-27

Noblet, C.L. and Teisl, M.F. 2015. Eco-labelling as sustainable consumption policy. Handbook of Research on Sustainable Consumption, edited by L.A. Reisch \& J. Thøgersen,70-83. Cheltenham: Edward Elgar

Peters, H.P., Lang, J.T., Sawicka, M. and Hallman, W.K. 2007. Culture and Technological Innovation: Impact of Institutional Trust and Appreciation of Nature on Attitudes towards Food Biotechnology in the USA and in Germany. International Journal of Public Opinion Research, 19 (2): 191-220

Pigors, M. and Rockenbach, B. 2016. Consumer Social Responsibility. Management Science Articles in Advance: 1-15

Ping jr, R.A. 2004. On assuring valid measures for theoretical models using survey data, Journal of Business Research. $57(2), 125-141$

Pivato, S., Misani, N. and Tencati, A. 2008. The impact of corporate social responsibility on consumer trust: the case of organic food. Business Ethics: A European Review, 17 (1): 3-12

Podsakoff, P.M., MacKenzie, S.B., Lee, J.Y. and Podsakoff, N.P. 2003. Common Method Biases in Behavioral Research: A Critical Review of the Literature and Recommended Remedies. Journal of Applied Psychology, 88 (5): 879-903

Probert, J., Koenig-Lewis, N., Stacey, K., Zhao, A. and Xuan, Y. 2014. Sustainable Water Consumption: the role of consumer behaviour in (re)shaping water utility business models. Conference paper. Graz Austria, Volume: ISIS Report \#6. https://www.researchgate.net/publication/259903676 (accessed July 10, 2016) 
Schwartz, S.H. 1992. Universals in the content and structure of values: theoretical advances and empirical tests in 20 countries. Advances in Experimental Social Psychology, edited by M. Zanna, 1-65. New York: Academic Press

Shan, Y., Yang, L., Perren, K. and Zhang, Y 2015. Household Water Consumption: Insight from a Survey in Greece and Poland. Procedia Engeneering, 119 (1): 1409-1418

Shaw, D., Shiu, E. and Clarke, I. 2000. The Contribution of Ethical Obligation and Self-Identity to the Theory of Planned Behaviour: An Exploration of Ethical Consumers. Journal of Marketing Management, 16: 879-894

Steg, L. and Vlek, C. 2009. Encouraging pro-environmental behaviour: An integrative review and research agenda. Journal of Environmental Psychology, 29: 309-317

Steg, L. 2015. Environmental psychology and sustainable consumption. Handbook of Research on Sustainable Consumption, edited by L.A. Reisch \& J. Thøgersen, 70-83. Cheltenham: Edward Elgar

Swaen, V. and Chumpitaz, R.C. 2008. Impact of Corporate Social Responsibility on Consumer Trust. Recherche et Applications en Marketing, 23 (4): 7-33

Syme, G.J., Nancarrow, B.E. and McCreddin, J.A. 1999. Defining the components of fairness in the allocation of water to environment and human uses. Journal of Environmental Management, 54: 51-70

Syme, G.J., Shoa, Q., Po, M. and Campbell, E. (2004). Predicting and understanding home garden water use. Landscape and Urban Planning, 68: 121-128

Syme, G.J. and Nancarrow, B.E. 2012. Protecting Natural Resources: Psychological and Contextual Determinants of Freshwater Conservation. Oxford Handbook of
Environmental and Conservation Psychology, 128-149. Oxford: Oxford University Press.

Thomas, C.W. 1998. Maintaining and Restoring Public Trust in Government Agencies and their Employees. Administration \& Society, 30 (2): 166-193

Trumbo, C.W. and O'Keefe, G.J. 2005. Intention to Conserve Water: Environmental values, Reasoned Action, and Information Effects Across Time. Society and Natural Resources, 18: 573-585

van Marrewijk, M. 2003. Concepts and Definitions of CSR and Corporate Sustainability: Between Agency and Communication. Journal of Business Ethics, 44: 95-105

Vitell, J.S. 2015. A Case for Consumer Social Responsibility (CnSR): Including a Selected Review of Consumer Ethics/ Social Responsibility Research. Journal of Business Ethics, 130 (4): 767-774

Waddock, S. 2004. Parallel Universes: Companies, Academics, and the Progress of Corporate Citizenship. Business and Society Review, 109 (1):5-42

Wells, V.K., Taheri, B., Gregory-Smith, D. and Manika, D. 2015. The role of generativity and attitudes on employees home and workplace water and energy saving behaviours. Tourism Management, 56: 63-74

Willis, R.M., Stewart, R.A., Panuwatwanich, K., Williams, P.R. and Hollingsworth, A.L. 2011. Quantifying the influence of environmental and water conservation attitudes on household end use water consumption. Journal of Environmental Management, 92: 1996-2009 